\title{
The potential of industry digitalization for improving environmental situation in the Russian regions
}

\author{
Inessa Vasileva $^{1, *}$ and Natalia Morozova ${ }^{1}$ \\ ${ }^{1}$ Chuvash State University, 29, Moskovsky Avenue, Cheboksary, 428000, Russia
}

\begin{abstract}
In today's rapidly changing conditions of economic development, which entail the emergence of new growth drivers, as well as the rapid pace of technological changes, new megatrends, new threats to the economic security and stability of territories and regional markets are emerging. In such a situation, only new approaches to the formation of strategies and justification of management decisions will make it possible to turn new threats into new opportunities and competitive advantages. The paper studies the concept and essence of the potential of digitalization of industry as a factor of sustainable development of the territory. The analysis of the dynamics of digitalization of the Russian Federation and the regions of the Volga Federal District is presented, the structure of the digital potential of the territories and their economic entities is presented. A method for calculating the potential of digitalization of the industry in the regions is proposed, and the main problems of its implementation are identified.
\end{abstract}

\section{Introduction}

The competitiveness of territories and their economic entities directly depends on innovative activities based on the knowledge economy and modern communication and information technologies. "It is the innovative competitive advantages of the region, in contrast to the limited natural resources, that can ensure its sustainable progressive development in the present and future" [1]. The higher the competitiveness of the region, the greater the potential (economic, investment, innovation, financial, digital, etc.) it has, and therefore increases the stability of the territory and the level of its economic security.

The issues of ensuring digital potential and sustainable development of the digital economy are considered in the works of various scientists, there are analytical reviews of the processes of digitalization, the analysis of the level of digitalization of countries is carried out, but all these studies interpret these concepts differently and use different indicators for evaluation. So Gorodnova N. V., Skipina D. L., Peshkova A. A. consider as a digital potential a set of resources, internal capabilities of economic entities for the implementation of the stages of the cycle of development of information technologies and functional areas of activity in which information technologies can be used. Kozlov A.V.

\footnotetext{
*Corresponding author: inka107@mail.ru
} 
and Tesli A. B. define digital potential as an integral indicator that reflects the current level and future opportunities for the use of digital technologies by an economic entity, taking into account the conditions of the external environment.

\section{Materials and methods}

The methods and principles of scientific generalization, comparative and system analysis, logical modeling, expert and statistical methods were used in the study, which together allowed to ensure the reliability and validity of theoretical conclusions and practical recommendations.

The methods of statistical-economic, monographic, computational-constructive and economic-mathematical methods of research with the use of information and computer systems were also used in the processing of information.

\section{Results}

In recent decades, there have been active processes of development of digital innovations and cyberphysical systems ("cyberphysical system" - CPS), which today are an integral part of the life support systems of citizens and ensuring the economic security and sustainability of territories. Their introduction into production forms the "Industry 4.0", which was formed during the Fourth Industrial Revolution (https://ec.europa.eu/). Digitalization is becoming a key component of modern innovation policy at all levels. As a result, a new branch of economic activity - the digital economy-is being formed to take into account and assess the impact of these processes on society and the economy [1,2].

If we proceed from the classical definition of the economy, the digital economy should be understood as "economic production, as well as a set of relations that develop in the system of production, distribution, exchange and consumption based on the use of digital technologies". However, to date, there is no unified definition and understanding of the components of the digital economy. The digital economy can be understood as "a global network of economic and social activities that are supported through platforms such as the Internet, as well as mobile and sensor networks" (https://www.oaic.gov.au). This "new economy, knowledge-based and digital technologies, in which the formation of new digital skills and opportunities in society, business and government" (https://openknowledge.worldbank.org), and "a form of economic activity that occurs through billions of examples of network interaction of people, businesses, devices, data and processes" (https://www2.deloitte.com) and "economy, which thanks to the development of digital technologies, the rise in labor productivity, competitiveness, cost reduction, creation of new jobs, reducing poverty and social inequality" (https://openknowledge.worldbank.org), etc. In Russia, the concept of "digital economy" is indirectly formulated in the Strategy for the Development of the Information Society of the Russian Federation for 2017-2030: "economic activity in which the key factor of production is data in digital form; processing large volumes of this data and using the results of their analysis in comparison with traditional forms of management can significantly increase the efficiency of various types of production, equipment, storage, sale, delivery of goods and services" (http://www.kremlin.ru ). According to the minutes of the meeting of the sub-commission on Digital Economy of the Government Commission on Digital Development, the Use of Information Technologies to Improve the Quality of Life and Business Conditions of 27.09.2019 No. 577, the digital economy is an activity for the creation, dissemination and use of digital technologies and related products and services. 
In this regard, it is important to identify the driving forces of the formation and development of the digital economy [3,4,5]. First of all, it is necessary to consider the digital economy from the point of view of the development of innovative potential, where the driver of growth is new knowledge and data. By 2025, the global volume of digital data, according to IDC, will grow to 175 zettabytes (40 zettabytes in 2020). Most of this data will be constantly changing in real time. Today, the largest big data markets by revenue are the United States (53\% of the global market, \$ 100 billion), Japan (5.1\%, \$9.6 billion) and the United Kingdom (4.9\%, $\$ 9.2$ billion). The Russian market still occupies a small share and is estimated at 45 billion rubles (https://rg.ru ).

Secondly, one of the main rules for the development of the modern economy is to meet the needs of the population and ensure comfortable consumption of products, works and services through the development of logistics services. "Servicization" today is the basis of the innovation process and the impetus for the development of the digital economy, aimed at creating flexible business models focused on the individualization of consumption.

Third, digitalization creates new opportunities for the effective promotion of information and financial flows that accompany material, i.e. ensures active interaction of all parties at all stages of the innovation process $[6,7]$.

New opportunities and forces of the digital economy aimed at ensuring the economic security and sustainability of territories contribute to the formation of an innovation ecosystem with functional relationships and relations of various actors. The digital transformation of such an "innovation ecosystem" provides new opportunities for the transfer of knowledge and the organization of network communications, where ready-made solutions and data are exchanged [8].

V. Dolfsma notes that a decentralized communication structure reduces transaction costs and increases synergy for the innovation ecosystem and the economy as a whole [9], and digitalization makes it possible to create such structures quickly and at the lowest cost. In 2020, entire sectors were significantly changed by the profound phenomenon of "digital transformation": media, retail, hospitality, automotive, healthcare, education, air transport, insurance, etc. The acceleration caused by COVID-19 was not limited to the use of digital tools. It has also led to a significant" deepening " of government, business, and private understanding of the value of digital transformation.

The high speed of the innovation life cycle also requires the acceleration of bureaucratic processes, which is why the state and business today assign a key role to digital technologies when developing development strategies, realizing that the technological and social base for transformation has actually been formed. The importance of digital technologies in our lives has reached new heights, and more and more people spend more and more time on the Internet, solving more and more tasks there: the number of Internet users in the world in January 2020 increased to 4.54 billion, which is $7 \%$ more than in 2019; the number of social media users reached 3.80 billion; more than 5.19 billion people use mobile phones (compared to 2019, an increase of 124 million $(2.4 \%)$ ) (https://www.web-canape.ru).

If we consider digitalization as a condition for increasing the competitiveness and sustainability of the territory, it is necessary to take into account the fact that most competitiveness ratings do not take into account the level of digitalization [10,11]. However, some integrated indexes have recently begun to adapt to the new demands of digitalization. For example, the NRI (Networked Readiness Index) 2020 is focused on digital transformation, calculating the rating based on indicators for 60 variables. According to the NRI, at the end of 2020, Russia ranked 48th out of 134 countries (https://networkreadinessindex.org). The International Digital Economy and Society Index (I-DESI) uses 24 data sets to analyze trends and compare the digital performance of 45 countries. The analysis includes 27 EU member states and 18 non-EU countries that have a 
global distribution. In the final ranking for 2018, Russia ranked 35th out of 45 (https://ec.europa.eu).

In general, we can say that the Russian economy has a significant digital potential. The importance of its implementation is also enshrined in the Program "Digital Economy of the Russian Federation" and in the Decree of the President of the Russian Federation "On the Strategy for the Development of the Information Society in the Russian Federation for 2017-2030". According to this decree, one of the directions of development of information and communication technologies in the country is the industrial Internet, that is, the emphasis is on the development of the digital potential of the industrial sector. The high role of the development of technologies for collecting and processing big data accumulated by industrial facilities is also noted.

The index of digitalization of business in the manufacturing industry in Russia according to the calculations of the Institute for Statistical Research and Knowledge Economics of the Higher School of Economics in 2018 was equal to 35-the third place among 11 types of economic activity [12] (Fig. 1).

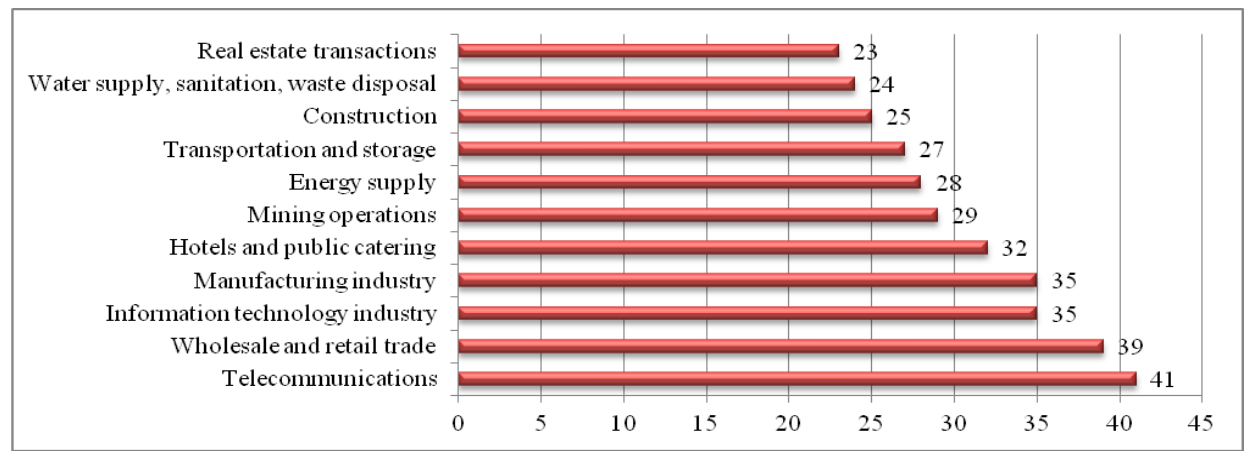

Fig. 1. Business Digitalization index by type of economic activity for 2018 .

The business Digitalization index characterizes the level of use of broadband Internet, cloud services, RFID technologies, ERP systems, and the involvement of business sector organizations in e-commerce. Most modern organizations use broadband Internet, their share ranges from $76.3 \%$ to $93.8 \%$. As for the use of cloud services and ERP systems, there are clear leaders-telecommunications (36.4\% and 41.4\%) and wholesale and retail trade (36.2\% and 34.5\%); Electronic sales are also actively used here $(27.3 \%$ and $28.6 \%$, respectively). RFID technologies are actively used in telecommunications (12.5\%) and manufacturing (11.4\%). Indicators of the share of organizations using digital technologies in the total number of organizations in the extractive industry occupy average positions [12] (Fig. 2).

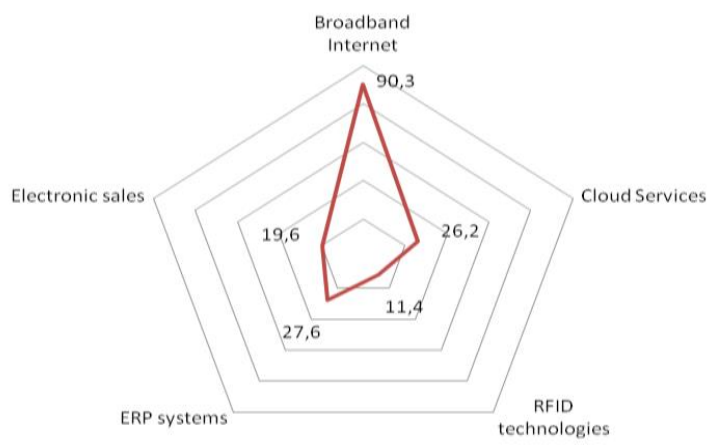


Fig. 2. The intensity of the use of digital technologies in the organizations of the manufacturing sector in $2018, \%$.

In general, the value of the business digitalization index in the federal districts varies from 23 in the Ural Federal District to 32 in the North-Western Federal District (Fig. 3).

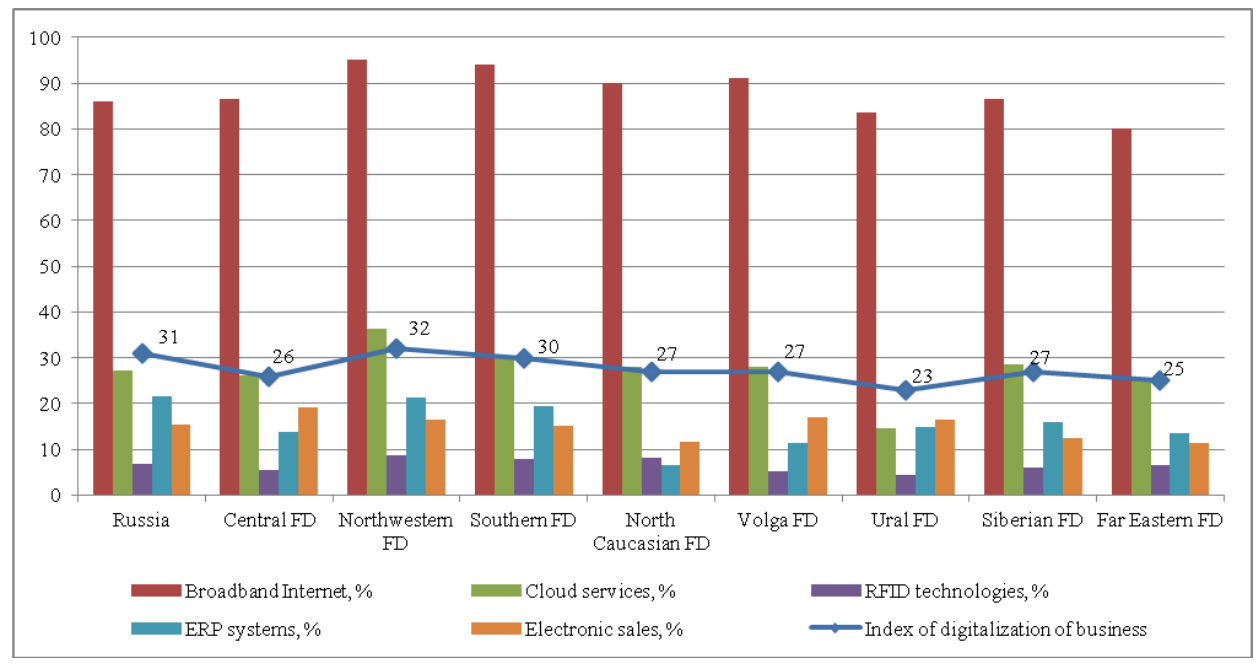

Fig. 3. Business Digitalization Index and the intensity of digital technology use in the Federal Districts of the Russian Federation for 2018.

Among the regions of the Volga Federal District, the first place in the business digitalization index is occupied by the Udmurt Republic (31 - at the level of the Russian Federation) due to the high proportion of organizations using broadband Internet, cloud services and RFID technologies. The outsider is the Republic of Mordovia with an indicator of 23 [12].

It should be noted that it is the development of the manufacturing sector, its technical and digital modernization that determines both the increase in the competitiveness of the national economy and the pace of economic growth of the country, but this requires a high digital potential [13].

The concept of digital potential, as well as the digital economy, is not unified. Therefore, the problem of determining the digital potential as an integral indicator that allows us to assess the capabilities of territories and its economic entities to transform business processes is one of the most relevant today. Often, the concept of digital potential is equated with the concept of innovative potential, which also has no unambiguous definition. However, it should be noted that innovation and information potential are not a substitute for digital potential, these types of potentials are related in relation to digital. To solve the problem, we turn to the classical definition of potential. Potential in a broad sense is understood as "the means, reserves, sources available and able to be mobilized, put into action, used to achieve a certain goal, implement a plan, solve a task; the capabilities of individuals, society, and the state in a certain area" (https://gufo.me).

Based on the above analysis, international indices that determine the level of development of digital technologies in different countries and the classical definition of potential, digital potential can be understood as a characteristic of the ability of economic systems to build a long-term more efficient information management system through the use of digital technologies in regional markets, territories, industries, etc. and to increase digital literacy among specialists in the real sector of the economy and in the field of public and municipal administration (Fig.4). 


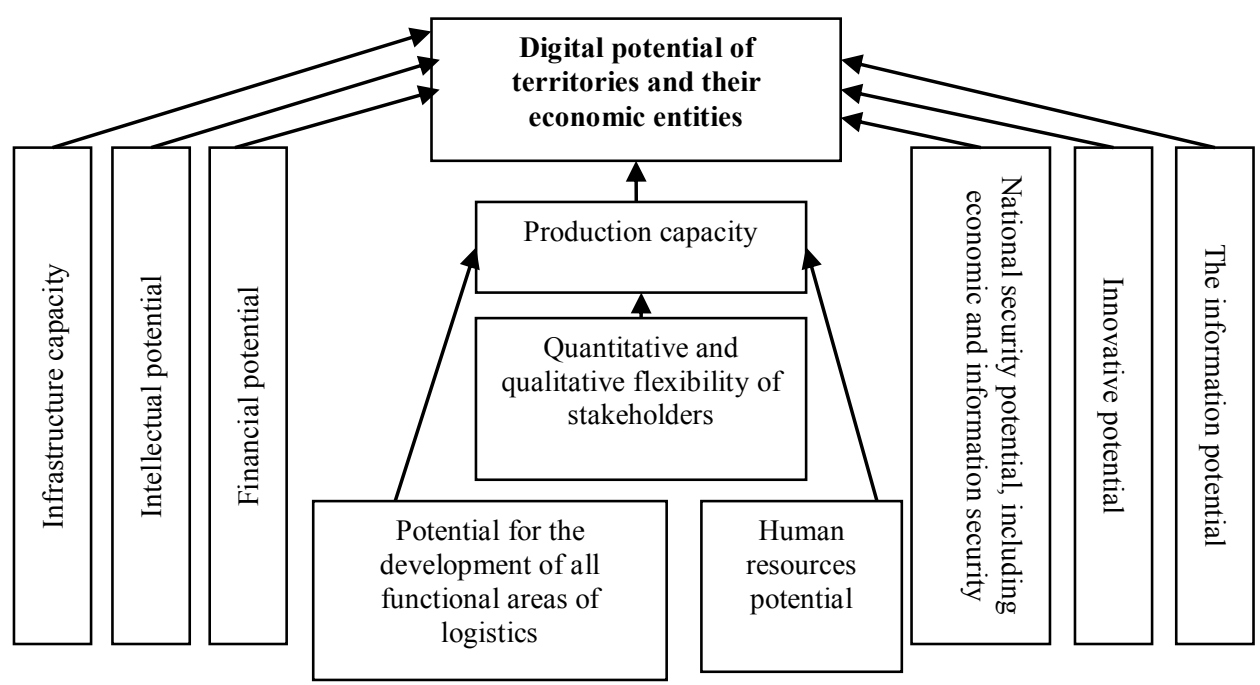

Fig. 4. Structure of the digital potential of territories and their economic entities.

Digital potential for a particular industrial enterprise is an integral indicator that reflects the state and availability of resources, the processes of product development and sales, the production process, the stages of procurement, the level of development of logistics processes, and the organization of accounting [14]. However, here the concept of digital potential will be incomplete if we do not take into account the interaction of economic entities with key participants in the movement of goods. That is, it is necessary to take into account indicators that reflect the quantitative and qualitative flexibility of stakeholders [15].

Thus, the methodology for assessing digital potential includes the following steps:

- identification of evaluation indicators and their measurement tools;

- grouping of indicators in the areas of management and decision-making;

- bringing the indicators to a comparable form;

- calculation of integral indicators;

- summing up the results, identifying "bottlenecks";

- development of specific measures aimed at the growth of digital potential.

\section{Conclusion}

When developing a program and strategy for socio-economic development, it is important to take into account the need to ensure economic security and digitalization as a key condition for the development of "Economy 4.0".

Digital challenges require the creation of digital networks in the educational system, science, and for solving life situations. At the same time, the state should be the initiator and engine of innovation processes, and digitalization should be a key element of the innovation ecosystem. In these circumstances, the creation of a national research data infrastructure is simply necessary. We should actively work to support startups as engines of digital transformation with the help of large technology companies; change the regulatory framework to increase the investment and innovation potential of the economy; development of " smart networks "(pillars of digital transformation) in the commercial sector; ensuring data security and "information autonomy"; introducing new business models for small and medium-sized businesses; using Industry 4.0 to modernize the 
country's production capacities; achieving significant success in research, modernization and innovation in the field of digital technologies; introducing digital education throughout a person's life; developing the innovative potential of the country's society; to strengthen the interaction between science, industry and the state, which will strengthen the innovative potential of the country.

\section{Acknowledgments}

The reported study was funded by RFBR, project number 20-010-00683.

\section{References}

1. A.V. Babkin, Digital transformation of economy and industry: problems and prospects (Publishing house of Polytechnical Institute, $\mathrm{SPb}, 2017$ )

2. T. Ladykova, I. Vasilieva, E3S Web of Conferences 210, 13035 (2020) DOI: https://doi.org/10.1051/e3sconf/202021013035

3. T. Ladykova, I. Danilov, E3S Web of Conferences 210, 17026 (2020) DOI: https://doi.org/10.1051/e3sconf/202021017026

4. N.V. Tumalanov, I.N. Urusova, T.A. Zerfos, EurAsian Journal of BioSciences 14(1), 593-599 (2020)

5. I.G. Salimyanova, A.A. Novikov, E.V. Novikova, Journal of Environmental Treatment Techniques 7(4), 654-658 (2019)

6. I.V. Zhukovskaya, M.V. Shinkevich etc, Espacios 39(9), 26 (2018)

7. T.V. Pogodina, T.V. Muzhzhavleva, N.L. Udaltsova, Entrepreneurship and Sustainability Issues 7(3), 1555-1564 (2020) DOI: https://doi.org/10.9770/jesi.2020.7.3(9)

8. Ya.M. Urinson, K.S. Panfilov, Business. Society. Power 2-3 (36-37), 117-125 (2020)

9. V. Dolfsma, State Failures: Society, Markets and Rules (Gaidar Institute Publishing House, Moscow, 2017)

10. T.V. Pogodina, T.V. Muzhzhavleva, N.L. Udaltsova, International Journal of Civil Engineering and Technology 9(10), 698-706 (2018) DOI: 10.15405/epsbs.2019.03.21

11. N.V. Tumalanov, E.N. Tumalanov, V.V. Ivanov, Eurasian Journal of Analytical Chemistry 12(5), 735-740 (2017) DOI: 10.12973/ejac.2017.00206a

12. G.I. Abdrakhmanova, K.O. Vishnevsky, L.M. Gokhberg etc, Indicators of the digital Economy: 2020: statistical collection (Higher School of Economics, Moscow, 2020)

13. I. Danilov, T. Ladykova, N. Morozova, E. Ilyina, Journal of advanced research in law and economics 1-8, 18-22 (2017) DOI: 10.14505/jarle.v8.1(23).03

14. A.V. Kozlov, A.B. Teslya, Bulletin of the Trans-Baikal State University 6, 101-110 (2019) DOI: 10.21209/2227-9245-2019-25-6-101-110

15. O.A. Romanova, Economy of Region 14(3), 806-819 (2018) DOI: 10.17059/2018-2-7 